\title{
Hard X-ray-Induced Valence Tautomeric Interconversion in Cobalt-o-Dioxolene Complexes
}

\author{
Thiago M. Francisco ${ }^{1}$, William Gee ${ }^{2}$, David A. Shultz ${ }^{3}$, Paul R. Raithby ${ }^{2}$ and Carlos B. Pinheiro ${ }^{1}$ \\ ${ }^{I}$ Department of Physics, Universidade Federal de Minas Gerais, Belo Horizonte - MG, Brazil. \\ ${ }^{2}$ Department of Chemistry, University of Bath, Bath, United Kingdom. \\ ${ }^{3}$ Department of Chemistry, North Carolina State University, Raleigh, NC, USA. \\ E-mail: cbpinheiro@ufmg.br
}

$\left[\mathrm{Co}(o \text {-diox })_{2}(4-\mathrm{CN}-\mathrm{py})_{2}\right]$-benzene $\left(o\right.$-diox $=3,5$-di-t-butylsemiquinonate $\left(S Q^{\circ}\right)$ and/or 3,5-di-t-butylcatecholate $\left(\mathrm{Cat}^{2-}\right)$ radical; 4-CN-py $=4$-cyano-pyridine) (1) (figure 1$)$ is $a$ valence tautomer [1] showing a charge transfer between the redox-active ligand and the cobalt accompanied by a change of metal ion spin state [2]. Such processes are reversible and create two switchable electronic states $h s-\left[\mathrm{Co}^{2+}\left(\mathrm{SQ}^{*}\right)_{2}\right]$ and $l_{s-}$ $\left[\mathrm{Co}^{3+}\left(\mathrm{SQ}^{\circ}\right)\left(\mathrm{Cat}^{2-}\right)\right]$ that can be interconverted by external stimuli such as temperature and illumination [3]. In 1 pure $h s-\left[\mathrm{Co}^{2+}\left(\mathrm{SQ}^{*}\right)_{2}\right]$ state is found above $290 \mathrm{~K}$ whereas almost pure $l s-\left[\mathrm{Co}^{3+}\left(\mathrm{SQ}^{\circ}\right)\left(\mathrm{Cat}^{2-}\right)\right]$ state is observed below $100 \mathrm{~K}$ depending on the thermal history of the sample. The structure of 1 was further investigated by single crystal $\mathrm{X}$-ray diffraction techniques using hard X-ray radiation $(0.48590 \AA)$ in temperatures ranging from $300 \mathrm{~K}$ down to $30 \mathrm{~K}$. A single crystal suitable for X-ray diffraction experiments was mounted in a capton loop and transferred to the X-ray diffraction goniometer of the IL9 Beamline of the Diamond synchrotron radiation facility [4]. Initially the sample was fast cooled to $30 \mathrm{~K}$ and successively exposed to an X-ray beam without attenuation from 30 to $100 \mathrm{~K}$ (HAX) in the darkness. Afterwards, the same sample was fast cooled to $30 \mathrm{~K}$ a second time and then illuminated with an intense LED white light for 60s. After illumination, a new series of single crystal X-ray diffraction experiments was performed from 30 $\mathrm{K}$ up to $100 \mathrm{~K}$ (HAXWL) in the darkness, using an attenuated X-ray beam when compared with the first experiment run. The sample was then heated to $300 \mathrm{~K}$ and measured in the darkness, during slow cooling from 300 down to $30 \mathrm{~K}$ with an attenuated X-ray beam (Attenuated HAX). Surprisingly, 1 was found to present hard X-ray responsive behavior yielding a metastable $h s-\left[\mathrm{Co}^{2+}\left(\mathrm{SQ}^{\circ}\right)_{2}\right]$ redox isomer at temperatures near $30 \mathrm{~K}$ with $\mathrm{ca} .80 \%$ mole fraction conversion. Fast cooling of the samples from $100 \mathrm{~K}$ to $30 \mathrm{~K}$ followed by illumination with white light and attenuated hard X-rays beam radiation exposition also induced $c a$. $80 \%$ mole fraction conversion (Figure 2). 1 is the first valence tautomer displaying metastable mole fraction interconversion at low temperature investigated by single crystal X-ray diffraction techniques.

[1] Tezgerevska, T. et al. (2014). Coordination Chemistry Reviews, 268, 23-40.

[2] Ribeiro, M. A. et al. (2016). Crystal Growth and Design., 16, 2385-2393

[3] Schmidt, R. D. et al. (2010) J. Am. Chem. Soc.,132, 6261.

[4] H. Nowell, et al. (2012). J. Synchrotron Rad.,19, 435-441.

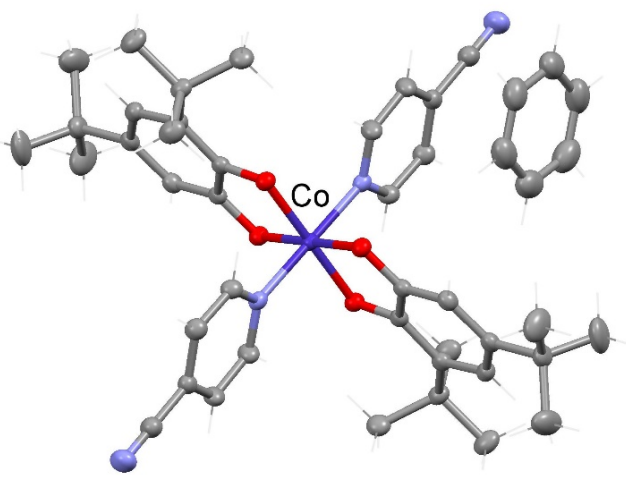

Figure 1: [Co(o-diox $\left.)_{2}(4-\mathrm{CN}-\mathrm{py})_{2}\right] \cdot$ benzene structure.

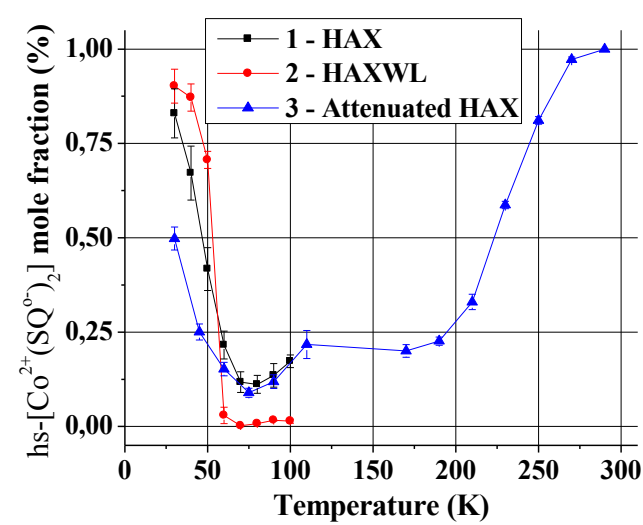

Figure 2: $\mathrm{hs}-\mathrm{Co}^{2+}$ mole fraction change during cooling (3) and during the metastable hs-[Co $\left.{ }^{+2}\left(\mathrm{SQ}^{-}\right)_{2}\right]$ redox isomer appearance $(1,2)$.

Keywords: Photo-induced valence tautomerism, dioxolene cobalt complex, X-ray diffraction. 